\title{
M. Termite, Vers la dernière ligne
}

\section{Rosa Galli Pellegrini}

\section{(2) OpenEdition}

\section{Journals}

\section{Edizione digitale}

URL: http://journals.openedition.org/studifrancesi/28046

DOI: 10.4000/studifrancesi.28046

ISSN: 2427-5856

\section{Editore}

Rosenberg \& Sellier

\section{Edizione cartacea}

Data di pubblicazione: 31 décembre 2006

Paginazione: 638

ISSN: 0039-2944

\section{Notizia bibliografica digitale}

Rosa Galli Pellegrini, « M. Termite, Vers la dernière ligne », Studi Francesi [Online], 150 (L | III) | 2006,

online dal 30 novembre 2015, consultato il 08 novembre 2020. URL : http://journals.openedition.org/ studifrancesi/28046; DOI : https://doi.org/10.4000/studifrancesi.28046

\section{Questo documento è stato generato automaticamente il 8 novembre 2020.}

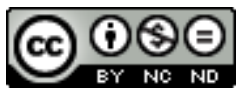

Studi Francesi è distribuita con Licenza Creative Commons Attribuzione - Non commerciale - Non opere derivate 4.0 Internazionale. 


\title{
M. Termite, Vers la dernière ligne
}

\author{
Rosa Galli Pellegrini
}

\section{NOTIZIA}

M. TERMITE, Vers la dernière ligne, Bari, Graphis ed., 2006, pp. 299.

1 Più di un centinaio di testi vengono presi in esame da Marinella Termite per tracciare una mappa della «fine» nel romanzo francese dei nostri giorni. L'interesse per questo tipo di ricerca nasce dalla costante apertura del romanzo contemporaneo a strutture innovative, anomale rispetto alle sequenze narrative del romanzo tradizionale. La studiosa si sofferma su quelle tecniche che il romanzo dell" "extrême contemporain" mette in atto per sconvolgere le abitudini di una lettura lineare al fine di moltiplicare le soluzioni, non più univoche, che il contesto della conoscenza offre oggi all'uomo per confrontarsi con la "realtà" che lo circonda. Da quanto emerge dalla lettura del saggio che contempla diverse forme di chiusura, portando numerosi e pertinenti esempi risulta una configurazione che la studiosa definisce "frattale", forma che meglio risponde alla mancanza di geometricità, alla quale il romanzo tradizionale aveva abituato il lettore. Ne risulta anche una poetica del romanzo nuova: non più "specchio" della realtà, ma luogo dove la scrittura crea una sua propria realtà. Gli autori scelti da Marinella Termite rappresentano quanto ad oggi si è affermato nel panorama del romanzo francese e costituiscono un corpus più che soddisfacente per appoggiare le tesi e le categorizzazioni della studiosa. Un'ampia bibliografia critica sui problemi della "soglia" e l'elenco dei testi citati chiude il pregevole lavoro. 